\title{
The role of domestic markets in international technological innovation systems
}

Håkon Endresen Normann and Jens Hanson

TIK Centre for Technology, Innovation and Culture, University of Oslo

Email: h.e.normann@tik.uio.no

Published in Industry and Innovation. Apr 2017

\begin{abstract}
This paper explores how countries in non-leadership positions can couple onto globally developing technological innovation systems (TIS) for renewable energy. The paper contributes to recent debates on relations between technological innovation systems and context, with a focus on how industries located in one country relate to the international TIS. Based on a survey of 102 firms in the offshore wind industry in Norway and semi-structured interviews, we find that even though Norwegian firms link up with international technological innovation systems, the lack of a domestic market represents a barrier. However, firms with activities in related industries and large firms are less exposed to this barrier. This poses a challenge as the offshore wind industry in Norway mainly consists of smaller firms. We therefore suggest that policies should aim to stimulate interaction between smaller suppliers and larger firms that potentially can act as intermediaries and provide access to international markets.
\end{abstract}

Keywords: technological innovation system, offshore wind, internationalisation, home markets, transnational linkages 


\section{Introduction}

Many countries actively promote the development of new renewable energy technologies linked to the on-going energy transition. The development of these technologies can be seen to take place globally, with some countries taking the lead. Germany and China for instance play important roles in photovoltaic deployment and manufacturing. However, most countries do not have leadership positions. This paper asks how such countries can couple on to the globally developing technological field of renewable energy.

To explore this we draw and expand upon the technological innovation system (TIS) approach, which has become a popular framework for studying the development of renewable energy technologies (Markard, Raven, \& Truffer 2012). This popularity has also been accompanied by critique contending that the framework has had a too narrowly defined national focus (Wieczorek et al. 2015, p. 4) and an underdeveloped understanding of geography (Binz et al. 2012).

As a response to this critique recent developments of the framework have moved towards integrating a spatial dimension with insights from economic geography and literature on global production networks in TIS analyses (Quitzow 2015a). It has for instance been demonstrated that individual countries do not necessarily need to develop entire supply chains domestically given the international dimension of TISs (Binz, Truffer, \& Coenen 2014; Binz et al. 2012; Vasseur, Kamp, \& Negro 2013). However, coupling onto emerging TISs is arguably not straightforward as access to for instance markets or investment capital is likely to be affected by geographical location (Coenen, Benneworth, \& Truffer 2012).

The objective of this paper is to contribute to these recent developments in the literature on international TIS and interrelations with national TISs, which has been suggested as an area in need of more research (Bergek et al. 2015; Wieczorek et al. 2015). We focus particularly on 
the role of home markets. The home market is an important dimension to industry formation due to the importance of local interaction and linkages among producers and suppliers (Fagerberg 1992; Freeman 1987). The importance of these local user-producer relations, and thus the home market, seems to differ between industry types. While process-intensive industries such as solar PV may emerge without the presence of local lead-markets (Quitzow 2015b), the home market has been identified as key in design-intensive industries such as wind power (Huenteler et al. 2016). The main aim of this paper is to investigate the extent to which weak home markets present a barrier for opportunities for providers of design-intensive products to link up with international TISs.

The following research question guides our analysis: How can industries in countries with weakly developing home markets link up with international technological innovation systems? In answering this question the paper makes two contributions to the TIS field in particular. First, we introduce a framework drawing on recent developments in TIS research. We extend the framework drawing on extant literature, to enable us to investigate two factors that might influence the degree to which market formation in other countries can compensate for the lack of access to local markets: Firm size and related industries. Second, we apply this framework to a study of the Norwegian supply industry to the international market for offshore wind.

In the following section, we further elaborate on the theoretical background for the paper. In section 3 we describe our data and methods. In section 4 we present and discuss the results from the analysis of our data from a survey and interviews before we discuss implications for theory and policy in the concluding section. 


\section{Theoretical background}

\subsection{Technological innovation systems and transnational linkages}

The technological innovation system approach sees innovation and technology development as an outcome of interaction between actors and networks guided by institutional frameworks. Further, the development and diffusion of a particular technology depends on the strength of a set of key processes or functions, which include knowledge development, entrepreneurial experimentation, guidance of search, market formation, legitimacy and resource mobilisation (see Bergek et al. 2008; Hekkert et al. 2007).

The TIS framework takes the focal technology as the starting point for defining system boundaries, and a TIS may thus span both geographical and sectorial boundaries (Bergek et al. 2008; Hekkert et al. 2007). Bergek et al. (2008) consider TISs to generally have a global character (p. 412) and Carlsson et al. (2002, p. 237) refer to the "global technological opportunities" of system actors. However, actors have unequal access to such opportunities as these might be constrained by inter alia geographical location (Coenen et al. 2012, p. 971).

Whilst not all actors have equal access to markets, knowledge and capital, all system functions necessary for the development of a technology might not need to develop in all regions or countries. Rather, TISs are embedded and often interact with broader contexts in both technological and geographical dimensions (Bergek et al. 2015). Empirical applications have however been criticized for lacking recognition of the spatial dimension, often resulting in the a priori system delineation on the national level (Truffer \& Coenen 2012). There is therefore a seeming contradiction between the international dimensions of TIS and importance of geographical, cultural, and political proximity between actors within TIS, as pointed out by Carlsson and Stankiewicz (1991). 
As a solution to this dilemma, Binz et al. (2014) suggest studying separate sub-systems (that may be national or regional) with linkages through an international TIS, rather than focusing on one global TIS or a single national TIS. System functions developing in one country can through transnational linkages spill over or have effect on other national sub-TISs (Gosens, Lu, \& Coenen 2015; Wieczorek et al. 2015). As a result, a weakly developed function in one country might not be problematic for the overall performance of the innovation system because transnational linkages compensate for partially weak functionality at the national level. In the following we discuss opportunities for creation of transnational linkages with regards to the particular function of market formation.

\subsection{Market formation in technological innovation systems}

Market formation fulfils an important function for the overall performance of a TIS through interaction with other system functions. Amongst others, market formation and access to markets is important for firms in a TIS given that it stimulates user-producer relations and network formation, seen as critical for innovation processes (Freeman 1995; Lundvall 1992). A relevant question for this paper is whether these user-producer relations need to occur at a local level or to what extent they can be established between actors in different countries. Empirical studies at firm and industry level have pointed to a positive correlation between the presence of a domestic market and export performance (Castellacci 2012; Castellacci \& Fevolden 2014; Fagerberg 1995; Lundvall et al. 2002). An important rationale behind market creation policies has therefore been based on the idea that the creation of "lead-markets" in one country will stimulate industry formation (supply) in the same country. This perspective has been challenged by Quitzow (2015b) who has found that the Chinese photovoltaic industry developed without the presence of a local lead-market. The main explanation provided for this success is the existence of transnational linkages or cross-country influences where for instance market growth in one country spills over to other countries (Quitzow 
2015b, p. 130). This suggests a possibility to develop a successful export industry without taking a leadership position in terms of market development.

However, the importance of local market interaction is likely to differ across sectors (Malerba \& Nelson 2011) and depending on the development stage of the technology in focus (Jacobsson \& Bergek 2004). The importance of geographical proximity or co-location is likely to be greater for nascent industries because "when the technology is complex and everchanging, a short distance might be important for the competitiveness of both users and producers" (Lundvall 1988, p. 355). However, when the technology is standardised, spillovers may be more effective across distances and actors in regions without local markets may be able to sell their products to markets in other sub-systems of the same TIS (Binz et al. 2014). The potential for spill-overs and transnational linkages that can bridge market access might also be affected by the complexity and structure of a particular industry. Huenteler et al. (2016) demonstrate that strong home market demand is particularly important in complex and design-intensive industries such as wind power. From this, we assume that firms' opportunities to link up with international TISs in the absence of a home market will vary depending on industry maturity or complexity. The offshore wind industry involves processes and technologies related to offshore logistics, foundations and electrical infrastructure, which increase complexity compared to onshore wind. Given this complexity, we expect local markets to be important for international competitiveness in the offshore wind industry, and thus influence opportunities for transnational linkages. This further motivates the inquiry of factors that might compensate for weak home market formation for industries that attempt to link up with international markets, which we discuss in section 2.3. 
We see a home market for offshore wind as either domestic offshore wind power projects or a domestic market for sub-contracts to large firms ${ }^{1}$. Domestic projects (developed by either domestic or foreign companies) are likely to stimulate user-producer relations and other benefits from having access to a local market. A market for sub-contracts may also form around large domestic suppliers to international markets. Thus, even in the absence of a domestic end-user market, smaller firms might be able to engage in user-producer interaction at the local level by supplying products or services to these larger firms.

\subsection{Factors affecting access to markets}

While sections 2.1 and 2.2 pointed towards the impact of spatial dimensions, extant literature has identified other factors that may influence processes of industry formation and international market access in the absence of a home market. First, the negative impact from a lack of a home market may be reduced through the presence of an internationally successful related industry (Porter 1998, pp. 101-5). Second, firm size is considered to be particularly important as larger firms have the resources to overcome sunk export costs and trade barriers (Castellacci 2012; Castellacci \& Fevolden 2014). In the following, we discuss how these factors might influence the possibility for firms and industries to access markets in other subTISs.

With regards to related industries, Frenken and Boschma (2007) use the concept of branching to explain how new industries can emerge through re-combinations of knowledge and other resources from existing industries. Thus, related industries can provide important input to the functions of knowledge production, entrepreneurial experimentation, and resource mobilisation (in particular human resources). A related industry might also provide

\footnotetext{
${ }^{1}$ We thank one of the reviewers for pointing to this distinction.
} 
opportunities to share activities in technology development, manufacturing, or marketing. In this sense, related industries can provide access to opportunities normally provided by a home market. For instance, exchange of $R \& D$ and joint problem solving may lead to better and more efficient solutions and firms gain faster access to information about technology and markets. The quality of this information might be positively correlated with geographical proximity due to lower transaction costs. Thus, the establishment of new industries through branching will often take place in the same regions that harbour the existing industries (Frenken \& Boschma 2007; Hansen \& Coenen 2015).

Branching processes can occur through diversification of firms in related industries, as well as through spin-offs and labour mobility from firms in established to new industries (Frenken \& Boschma 2007, pp. 3-4). The presence of many diversified firms in an emerging industry implies overlap of innovation system elements, where actors, networks, institutions and technologies are embedded in several TISs (or broader sectors) and linked through 'structural couplings' (Bergek et al. 2015). Structural couplings can contribute positively to the development of new industries. However, structural couplings can also be constraining as diversified firms that engage in different TISs might be subject to internal conflicts of interest. This brings us to the issue of firm size and what role incumbents can play in emerging industries. Insights from management and innovation studies provide somewhat inconclusive evidence as to how large, incumbent firms might contribute to innovation more generally (Dass 2000; King, Covin, \& Hegarty 2003; Rajagopalan \& Spreitzer 1997), and thus more specifically to sustainability transitions. On the one hand, most firms pursue diversification as one of several strategies to remain competitive, whilst they simultaneously attempt to strengthen their position in existing markets. Consequently, diversified incumbent firms might not fully commit to the diversified activities due to uncertainties and fear of cannibalising their existing products (Geels, Hekkert, \& Jacobsson 2008). Incumbents are often viewed as maintaining stability through the 
use of power to maintain status quo (Smink 2015). In this sense, incumbents can be seen as a barrier to the development of new technologies and system change (Geels 2014). Examples include the efforts by Exxon to keep climate change off the public and political agenda (Banerjee, Song, \& Hasemyer 2015) and how national states subsidise fossil based industries (Coady et al. 2015).

On the other hand, large incumbent firms can play a central role in the growth of new industries and technologies, even though these might in the future replace the technologies on which incumbents currently base their revenues. Although new entrants (often small start-ups) are important for developing new technologies, these will often fail due to lack of political clout and limited resources (Geels et al. 2008). Large incumbents have these resources and can accelerate innovation processes. Larger firms benefit from greater R\&D resources and ability to scale (Utterback \& Suarez 1993). Hence, these organisations have high technical knowledge and technical potential (Damanpour 1992). Moreover, size can allow access to financial resources denied to smaller firms that provide leeway to tolerate setbacks due to unsuccessful innovations (Damanpour 1992; Dass 2000). Consequently, Hockerts and Wüstenhagen (2010) argue that large firms might play a crucial role in the development of a range of new renewable energy technologies.

King et al. (2003) note that the impact of firm size on innovation will differ depending on the stages of the innovation process and the types of innovation. This is because small and large firms possess different qualities important for innovation. For instance, small firms may be particularly responsive to market changes, more agile, and more willing to accept risk. Larger firms, as pointed to above, often possess greater manufacturing, marketing, sales, and/or financial resources that small firms may need to exploit innovations (Dass 2000; King et al. 2003). Further, as a product or industry matures, manufacturing competence becomes more important as the focus shifts from technology innovation to efficiency (King et al. 2003). 
Small firms can therefore be seen to excel at product innovations and large firms excel at process innovations. We see this as important for two reasons. First, a logical continuation of the argument here is that large and small firm can possess "complementary innovationenhancing resources" (King et al. 2003). In other words, we might find that small niche firms and large incumbent firms will find it mutually beneficial to collaborate rather than compete. Second, large firms may play an important role both through their direct engagement in the development of a new industry and as an intermediary by helping smaller firms link up with other actors in the offshore wind technological innovation system (Acs \& Terjesen 2013; Howells 2006). For instance, in studies of the formation of technology-based firms in Sweden, James Utterback and colleagues found that large firms played a central role in providing finance and early markets for new firms (as cited in Carlsson \& Stankiewicz 1991, p. 108). Similarly, Dewald and Truffer (2012) have shown that the presence of larger firms that can act as intermediaries can compensate for weak market formation.

Summing up, related industries and firm size are factors that might affect the possibility for actors in one sub-TIS to access markets in other sub-TISs when there is a lack of local market formation. However, considering the role of incumbents and uncertain commitment from diversified firms, overlaps between related industries can both facilitate and constrain the growth of an emergent technology (Bergek et al. 2015, p. 54).

\subsection{Propositions}

The above leads us to three propositions that guide the analysis. First, a lack of a home market is likely to negatively influence the ability for industries in non-leader countries to link up with international technological innovation systems. Yet, cross-country spill-overs from strong market formation in other sub-systems might to some extent counter this negative effect (Quitzow 2015b). Second, larger (often incumbent) firms (from related sectors) are likely to be 
less affected by the absence of a home market and may offer opportunities for transfer of resources or access to customers for small and medium companies in latecomer contexts. Third, the presence of firms and markets in closely related industries (e.g. the petro-maritime industries in Norway (Vatne 2008)) can offset effects of weaknesses in market formation in domestic TISs.

\section{Case selection and methods}

To empirically explore our propositions and answer our research question, we analyse the case of offshore wind in Norway. Bergek et al. (2015, p. 61) point specifically to the internationalization of the offshore wind industry as relevant to study as an international TIS. In this industry important transnational linkages between nationally delineated TISs have been identified. In particular, knowledge development, entrepreneurial experimentation, and market formation may be rooted and nurtured in different countries, but contribute to the performance of an international TIS (Binz et al. 2014).

The international market for offshore wind power (OWP) has seen significant growth in recent years (EWEA 2015) and is expected to continue to grow in the coming years (Smith, Stehly, \& Musial 2015, p. 25). This growth has led a number of Norwegian firms (many with related activities in oil \& gas and maritime industries) to explore international markets given weak domestic market formation (Normann 2015; Steen \& Hansen 2014). We thus see the offshore wind industry in Norway as a suitable case to study opportunities and barriers for linking up with an international TIS.

For this study, we have mobilised multiple data sources, including a survey of Norwegian offshore wind firms and in-depth interviews. First, we conducted initial scoping interviews with stakeholders in the Norwegian offshore wind industry. Interviews were semi-structured and individually tailored in order to exploit the specific knowledge of each interviewee. 
Insights from these interviews and from the reviewed literature were then used to develop our propositions presented in section 2.4 and allowed us to identify variables for the statistical analyses (Bennett \& Braumoeller n.d.).

Second, based on the propositions linked to the role of home market, firm size and related industries, we constructed a survey. The sample for the survey was put together based on industry reports, membership of industry organisations, and desk research. The criteria for inclusion in the sample was that the firm had to be located in Norway, and that the firm had delivered, or had ambitions to deliver, products or services to the offshore wind industry. We received 110 responses from the original sample of 155 firms. After cleaning up the data by removing unreliable or incomplete responses ${ }^{2}$, we were left with 102 responses (66\%) for our analysis. Survey respondents were CEOs or managers of offshore wind activities. The survey was conducted via telephone in February 2015 and each interview lasted approximately 20 minutes. Data on total full-time equivalents for each firm was obtained from public national registries by use of the proff.no website and subsequently added to the dataset.

Third, following an initial analysis of the survey data, we conducted additional semistructured interviews with firms making sure to capture both small and large firms, and both dedicated offshore wind firms and diversified firms. This allowed us to further investigate how the statistical results made sense at a firm level (Mahoney \& Goertz 2006, p. 231), and to explore possible explanations for the statistical outcomes. In total we draw upon 19 interviews in the qualitative part of the analysis. The interviews were transcribed and coded in Nvivo according to the concepts presented in section 2 . Table 1 provides an overview of the interviews and how we refer to these in the analysis.

\footnotetext{
${ }^{2} 6$ of the firms responded that they had previously delivered products or services to the OWP industry, but that they no longer had any ambitions to do so. These firms were not asked to complete the survey.
} 
Table 1

Overview of interviews

\begin{tabular}{|c|c|c|c|}
\hline Code & Role & Type of organisation ${ }^{3}$ & Date of interview \\
\hline LDI1 & Senior Vice President & Large diversified firm & $11-4-2014$ \\
\hline LDI2 & Technology Manager & Large diversified firm & $12-21-2015$ \\
\hline LDI3 & Director of Wind & Large diversified firm & 2-14-2014 \\
\hline LDI4 & Executive Vice President & Large diversified firm & $1-25-2016$ \\
\hline LDI5 & Head of renewable energy & Large diversified firm & $6-17-2013$ \\
\hline LDI6 & Former Vice President & Large diversified firm & $4-29-2013$ \\
\hline SDI1 & Business development & Small-Medium diversified firm & $11-23-2015$ \\
\hline SDI2 & Managing Director & Small-Medium diversified firm & $11-18-2015$ \\
\hline SDE1 & Business developer & Small-Medium dedicated firm & $4-2-2013$ \\
\hline SDE2 & Owner & Small-Medium dedicated firm & $8-15-2013$ \\
\hline SDE3 & Project leader & Small-Medium dedicated firm & $9-18-2015$ \\
\hline SDE4 & Former manager & Small-Medium dedicated firm & $11-3-2014$ \\
\hline SDE5 & CEO & Small-Medium dedicated firm & $12-12-2015$ \\
\hline RND1 & Director & R\&D organisation & $3-3-2013$ \\
\hline RND2 & Director & R\&D organisation & $8-9-2013$ \\
\hline IEX1 & Director & Industry organisation & $11-21-2014$ \\
\hline IEX2 & Industry expert & Multiple organisations & $6-12-2014$ \\
\hline IEX3 & Former Director & Industry organisation & $3-8-2013$ \\
\hline IEX4 & Industry expert & Financial support institution & $10-28-2015$ \\
\hline
\end{tabular}

\section{Results}

The offshore wind industry has so far developed mostly around activity in the North Sea.

Policy driven markets have developed primarily in Germany and the UK, with a supply industry emerging also in other (mostly neighbouring) countries. For instance, the Dutch industry is well represented across the value chain based on competences and infrastructure

\footnotetext{
${ }^{3}$ Respondents LDI3 and LDI4 from the same organisation, but with different roles. Respondents LDI2 and LDI6 from the same organisation. Also with different roles.
} 
from maritime construction and engineering (Wieczorek et al. 2015). Wieczorek et al. (2015) find that transnational linkages between nationally delineated TISs can compensate for weak market formation in Denmark and the Netherlands and they describe the European offshore wind TIS as quite integrated. However, they also find that strengthening the local market formation in the Netherlands could motivate domestic entrepreneurial activities of smaller firms, which would strengthen the overall performance of the European TIS.

Offshore wind firms in Norway target these international markets, either directly or through engagement with intermediary firms. Figure 1 shows the distribution of firms along a supply chain for offshore wind. Nearly half of the Norwegian firms are primarily engaged in logistics \& vessels and in various consultancy and $R \& D$ services. In addition, a number of firms work with foundations or deliver other services related to subsea technology. So far, Norwegian firms have taken only a modest slice of the international offshore wind market. Export Credit Norway estimates that Norwegian companies' total international sales to the offshore wind industry was 400-480 million euros in 2015 accounting for an estimated 5 percent of deliveries to international offshore wind projects since 2010 (Make Consulting 2016). There are currently only two companies that own and develop offshore wind parks (Statoil and Statkraft ${ }^{4}$. Thus, the market of interest in this paper is the sub-market for suppliers to offshore wind power projects. So far no offshore wind parks have been constructed in Norway, and the only offshore wind power that has been commissioned is a single floating test turbine that was connected to the grid in 2009.

\footnotetext{
${ }^{4}$ In 2015, Statkraft announced that the company would not make any further investments in offshore wind.
} 


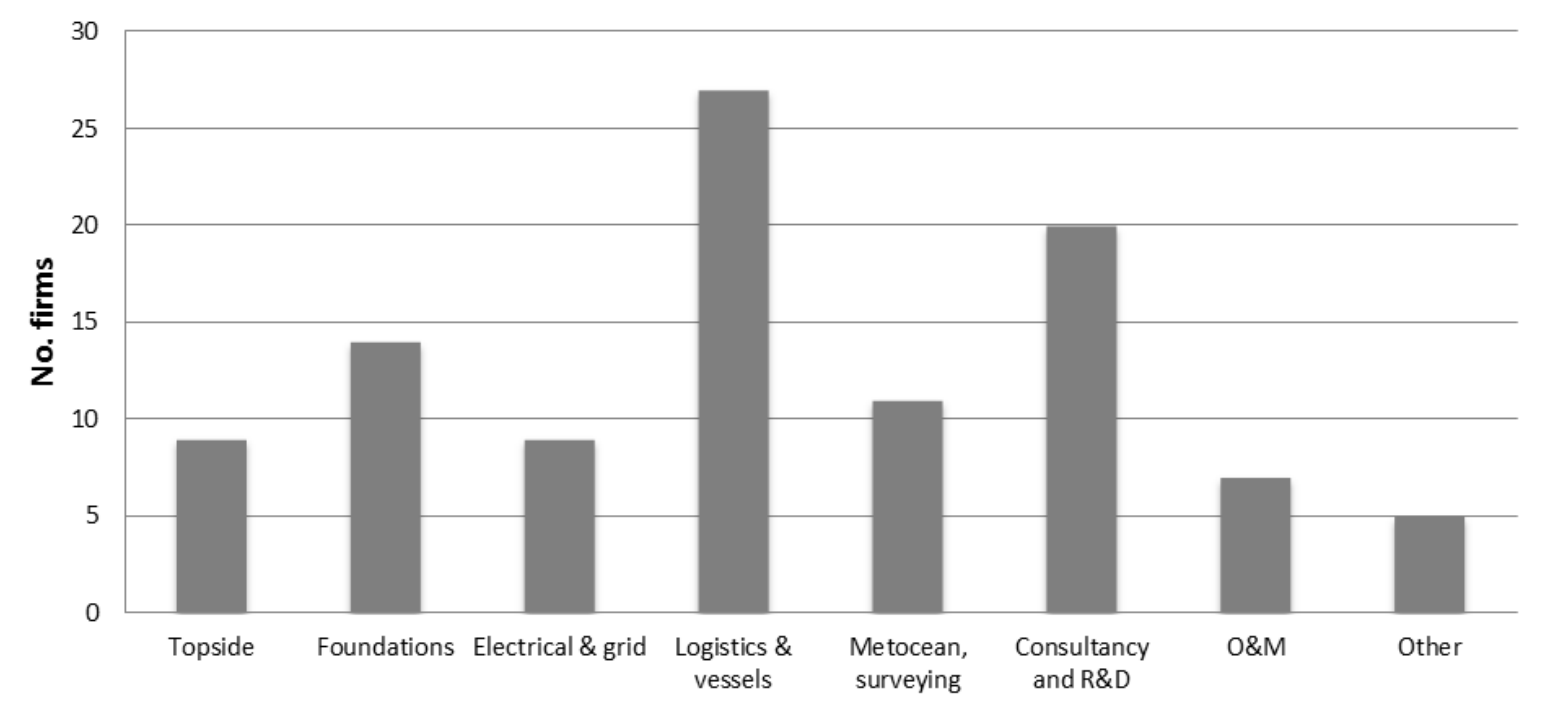

Figure 1. Distribution of firms along supply chain for offshore wind. Source: Survey data.

In the following, we describe further the population of surveyed firms based on firm size, level of dedication towards offshore wind, and relation to other industries. In table 2, we have grouped the survey respondents depending on how important they consider offshore wind to their overall business. 28 per cent regard offshore wind as a core activity and we label these as dedicated OWP firms. 41 per cent of the firms regard offshore wind as a supplement and another 31 per cent see offshore wind as a future or not important area for their business. We label these firms as diversified OWP firms. Thus, from table 2 we can see that most firms are diversified, which is in line with previous investigations of offshore wind in Norway (Hansen \& Steen 2015; Volden et al. 2009). We also note that the diversified firms are on average larger than the dedicated firms (average total full-time equivalents). However, the dedicated firms invest more in OWP both measured by full-time equivalents (FTEs) in absolute numbers and by share of turnover connected to OWP. From table 2, we can also see that nearly half of the diversified firms (supplement: 47 per cent, future or not important: 44 per cent) operate primarily in the petro-maritime industries. We return to this point in a discussion about related industries in section 4.3 . 
Table 2

Distribution of firms based on importance of offshore wind to firm

\begin{tabular}{|c|c|c|c|c|}
\hline \multirow[b]{2}{*}{ Importance of offshore wind } & \multirow{2}{*}{$\begin{array}{l}\text { Dedicated } \\
\text { Core }\end{array}$} & \multicolumn{2}{|c|}{ Diversified } & \multirow[t]{2}{*}{ Total } \\
\hline & & Supplement & Future or not important & \\
\hline Percentage of sample & $28 \%$ & $41 \%$ & $31 \%$ & $100 \%$ \\
\hline $\begin{array}{l}\text { Average total full-time } \\
\text { equivalents (FTE) }\end{array}$ & 250 & 490 & 219 & 337 \\
\hline Average full-time equivalents & & & & \\
\hline $\begin{array}{l}\text { (FTE) dedicated to } \\
\text { offshore wind }\end{array}$ & 40,2 & 10,2 & 2,8 & 16,0 \\
\hline $\begin{array}{l}\text { Share of turnover from } \\
\text { offshore wind }\end{array}$ & $43,5 \%$ & $6,6 \%$ & $5,4 \%$ & 16,7 \\
\hline Primary sectors & & & & \\
\hline Offshore wind & $61 \%$ & $0 \%$ & $3 \%$ & $18 \%$ \\
\hline Oil \& gas & $14 \%$ & $21 \%$ & $16 \%$ & $18 \%$ \\
\hline Maritime & $7 \%$ & $26 \%$ & $28 \%$ & $22 \%$ \\
\hline Offshore and subsea & $0 \%$ & $10 \%$ & $6 \%$ & $6 \%$ \\
\hline Other & $18 \%$ & $43 \%$ & $47 \%$ & $36 \%$ \\
\hline
\end{tabular}

Table 3 presents a similar set of data, but in this table we have grouped the respondents according to total firm size. From this table, we can see that although OWP represents a small share of the total activity in the large firms, these firms still invest substantially in absolute numbers in offshore wind (average FTEs on OWP). Thus, we identify in our sample of the Norwegian offshore wind industry a group of smaller dedicated firms and a group of larger diversified firms having core activities in other markets. We expect both of these groups to be important for the overall Norwegian offshore wind industry. 
Table 3

Distribution of firms based on firm size

\begin{tabular}{llll}
\hline Firm size (total full-time equivalents) & $\begin{array}{l}\text { Small } \\
(<26 \text { FTEs) }\end{array}$ & $\begin{array}{l}\text { Medium } \\
(\mathbf{2 6 - 2 5 0} \text { FTEs) }\end{array}$ & $\begin{array}{l}\text { Large } \\
(>\mathbf{2 5 0} \text { FTEs) }\end{array}$ \\
\hline $\begin{array}{l}\text { Average full-time equivalents (FTE) } \\
\text { dedicated to offshore wind }\end{array}$ & 14 & 8 & 38 \\
Share of turnover from offshore wind & $27 \%$ & $10 \%$ & $6 \%$ \\
Primary sectors & $26 \%$ & $11 \%$ & $0 \%$ \\
Offshore wind & $19 \%$ & $17 \%$ & $16 \%$ \\
Oil \& gas & $19 \%$ & $26 \%$ & $21 \%$ \\
Maritime & $2 \%$ & $14 \%$ & $0 \%$ \\
Offshore and subsea & $34 \%$ & $32 \%$ & $63 \%$ \\
Other & 42 & 35 & 19 \\
$N$ & & & \\
\hline
\end{tabular}

\subsection{Role of the home market}

In section 2, we suggested that a lack of a home market might constrain actors' ability to link up to the international TIS. Previous studies have pointed to the absence of a domestic enduser market for offshore wind in Norway (Hansen \& Steen 2012; Normann 2015). Our data reflects this as 68 per cent of the respondents had mostly or exclusively international customers (see fig. 2), of whom nearly all were located in the North Sea region.

Simultaneously, figure 2 shows that despite the lack of a domestic end-user market about onethird of the firms target Norwegian customers, pointing to the presence of some system suppliers that can bridge access to international end-user markets. 


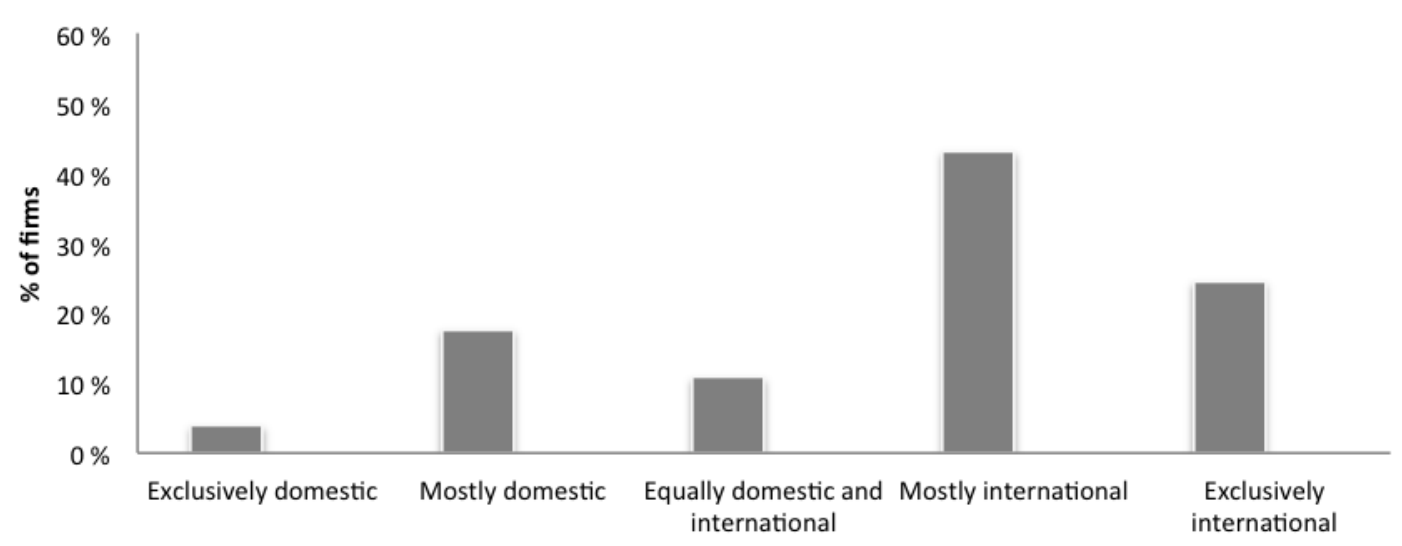

Figure 2. Location of most important customers (current and potential).

Given the direct or indirect international orientation of most firms, we see it as relevant to explore how the lack of a domestic end-user market affects the firms in our data. First, we asked if the absence of a domestic market makes it more difficult to succeed in the international market for offshore wind. 75 per cent of the respondents confirmed this to be true. One could expect many firms to agree with this statement, and we therefore should be careful in our interpretation of the responses. Nonetheless, this suggests that a majority of firms experience weak local market formation as a barrier for realising opportunities for internationalisation. However, 49 per cent of the firms that experience the lack of a home market as a barrier to internationalisation responded that international markets in the North Sea could partly or fully replace the need for a home market. Even though this points to the presence of cross-country spill-over from market formation in other sub-TISs, survey data suggests that a domestic market can be important for a large group of firms. We explore this further in our qualitative material. Interviews reveal that firms see a home market as important to firms' ability to export products and services to the international markets for offshore wind by enabling access to markets and by facilitating innovation. 
First, we look at market access factors. A majority of the interviewees considered a small home market as necessary to provide opportunities to test and qualify products and technology in order to be considered for international offshore wind projects. Proven technology is particularly important for offshore wind as repairing and replacing parts comes at a high cost compared to for instance onshore wind. A home market could give suppliers a chance to have the references needed to compete for international contracts, and lower the entry barrier for firms with relevant competences and technology that had not yet entered the market for offshore wind (SDE3). Thus, local market formation can be important for the development of other functions important for industry formation such as entrepreneurial experimentation.

A further barrier to market access that was pointed out by many of the interviewees was local content demands in the main international markets such as the UK (IEX3, LDI2, RND1, IEX2, LDI4, SDE5, SDE1):

There is considerable pressure on developers in the UK to use British suppliers. Everyone knows that this happens. Despite the fact that there is free competition, this is not how it works in practice (IEX3).

We interpret this as an example of how the national context influences actors' access to markets in the international TIS.

Moving on to factors related to innovation, many of the interviewees pointed out that large public R\&D investments have contributed to knowledge development for offshore wind. However, with no domestic market and weak financing of commercialisation of technology, much of the research gains and potential interaction between system functionality (i.e. market formation and knowledge development) remain unexploited (SDE5, RND2). Thus, due to weak local market formation public R\&D investments have not been fully exploited due to lack of what Foss (1998) calls complementary learning processes. 
However, perhaps the most pervasive comment from the interviewees came in reference to the issue of the "valley of death" (RND2, SDE5, RND1) and the role of demonstration projects in that it is "fairly easy to achieve development until you are close to moving from demonstration to large-scale. It is in the difficult financing of large-scale that a small domestic market could have helped" (RND2). This is because to get new technology to the market requires substantial resources:

There are many Norwegian companies that have developed solutions related to foundations, installation and operation. But these are solutions that they have been unable to take to the market. This is a conservative industry that is reluctant to try out new things. Unless you are a huge company and can afford to burn off half a billion NOK on full-scale demonstration - but there are hardly any Norwegian companies that have this opportunity - then you rely on having a test facility and funding of this test facility (SDE4).

Without a home market, firms need to either demonstrate technology in international projects or finance full-scale demonstration internally, which demands vast financial resources. This suggests that the need for a home market is more important for smaller firms who typically lack these resources. We deal with this issue in the subsequent section.

\subsection{Role of firm size}

In section 2, we proposed that firm size would influence the ability of firms to mitigate challenges associated with weak local market formation.

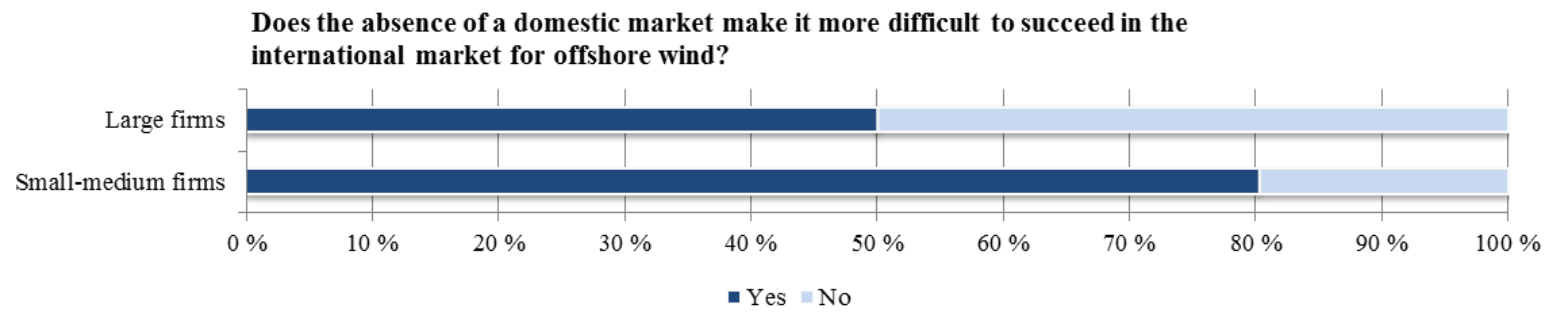

Figure $\mathbf{3}$ shows that small-medium sized firms were more likely to find the lack of a home market as a challenge for internationalisation than large firms. 


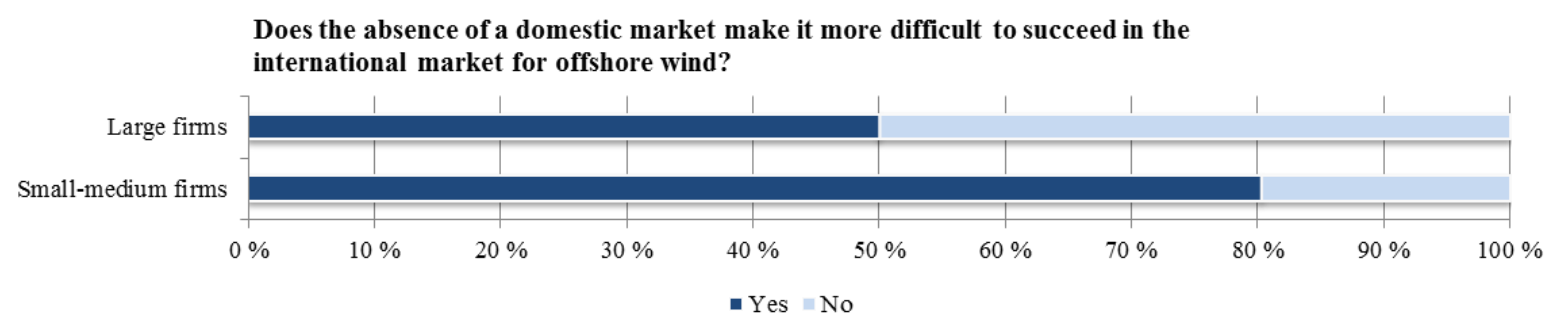

Figure 3 Pct. of firms that see a lack of home market as a challenge for internationalisation depending on firm size.

Note: Person's chi-square test of independence conducted. Chi square $=7.84 ; \mathrm{N}=93 ; \mathrm{p}$-value $=0.005$. Large firms: more than $€ 50 \mathrm{~m}$ revenue (2014).

In section 4.1, we showed that approximately half the firms recognised the international markets for offshore wind in the North Sea as either partly or fully replacing the need for a home market. Although

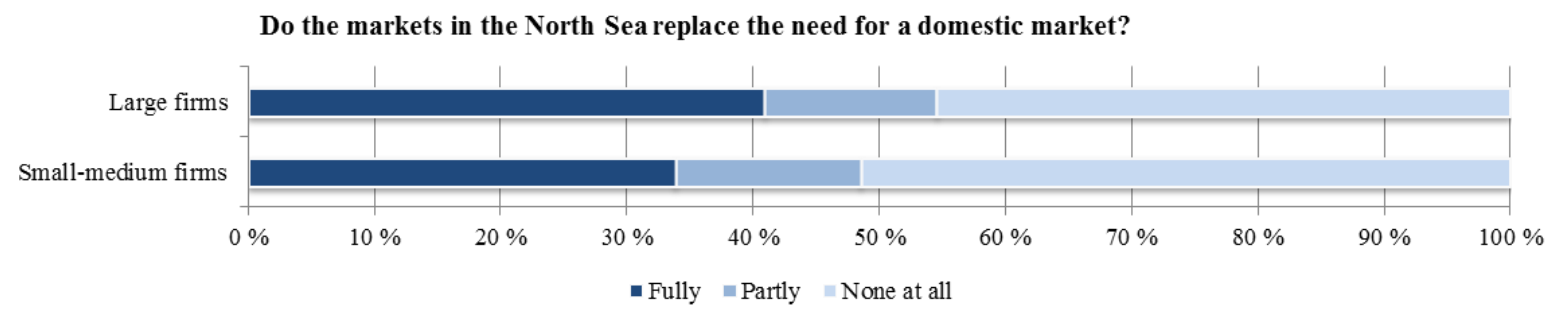

figure 4 shows that larger firms are somewhat over-represented in this group, we find the difference between large and small firms surprisingly small. Even though larger firms are more likely to have international activities, it is noteworthy that nearly half of these firms find little compensation for lack of access to local market in neighbouring markets. 


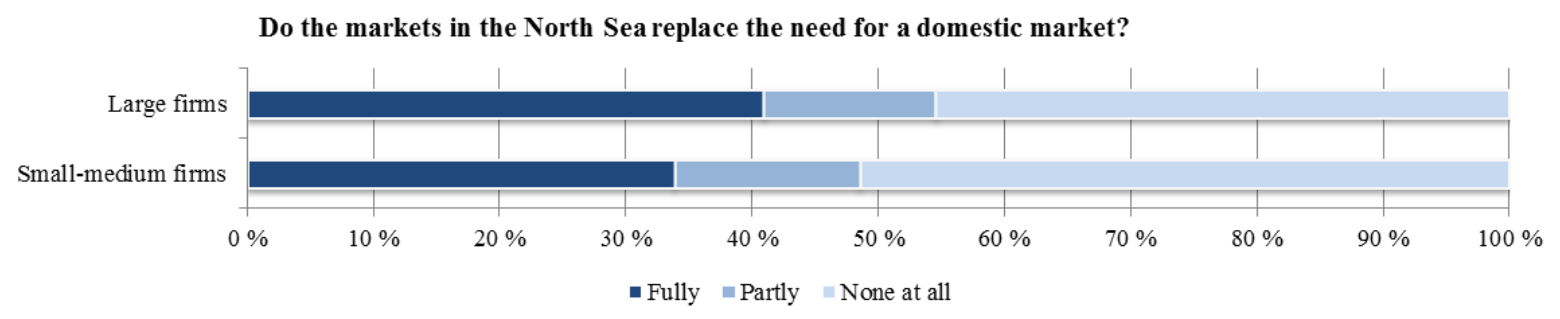

Figure 4 Pct. of firms that see North Sea offshore wind markets as a replacement for a home market depending on firm size.

Note: Large firms: more than $€ 50 \mathrm{~m}$ revenue (2014).

Nonetheless, figures 3 and 4 indicate that larger firms are less hampered by the lack of a home market. Thus, constraints on actors' access to markets in the international TIS are in part related to firm size. Evidence from interviews supports these findings. As one respondent from a large firm put it: "It does not make a difference to us whether we participate in a domestic or international market. It is like any other business. It does not matter where you build, as long as you build" (LDI6). By contrast, most of the small-medium sized firms pointed to challenges related to weak local market formation. We observe several reasons for this difference between large and small firms.

First, larger firms may have easier direct access to foreign markets. A number of respondents pointed out that larger firms are more likely to have established transnational linkages, particularly from their existing activities in the oil industry (RND1, RND2). A respondent from a large oil service company expressed that as a large firm it was easier to maintain direct relations with key players in the international offshore wind market:

\footnotetext{
"We are large enough to talk directly to Telnet or $A B B$ on these large projects (...) We had a relationship with $A B B$ from collaborating on several oil \& gas projects. So they looked upon us as a possible partner. And it was the same with Statoil and Hywind" (LDI4).
}

Second, large firms rely less on a domestic market due to available resources within the firm. In some segments of the offshore wind supply chain such as turbines, foundations and installation, large financial and research resources are needed to carry out the necessary steps 
in product development (LDI2). Further, large financial resources are also needed to bear technical risks often associated with the offshore wind industry (Kaldellis \& Kapsali 2013, p. 144). Finally, due to limited financial resources smaller firms find it harder to finance the costs of participating in large projects whilst waiting for financial settlements. Competing only in international markets increases this need for financial resources. The costs of entering a market abroad without a local bridging market are therefore seen as too high for many smaller suppliers of offshore technology and solutions:

"A small company that could have made good profits from the delivery of good services to the industry, cannot afford to make the investment required in the beginning to position itself in Germany and England" (LDI5).

Thus, for many smaller firms the main potential lies in the market for sub-contracts with larger domestic firms that can facilitate access to markets in other sub-TISs (SDE3, IEX2, IEX4):

"It is hard enough as it is to be a small company with a niche product. If you don't have anyone to sell it to that speaks the same language as you do, then it is virtually impossible (...) For small suppliers, the home market is large system suppliers, and not necessarily the end-user. In Norway, we have lacked that industrial locomotive” (IEX2).

There are companies that could fill this role in Norway. Although some of these firms have explored opportunities in offshore wind, this engagement has been limited and they have not taken up the role as industrial locomotives. However, two large incumbent energy companies (Statoil and Statkraft) have invested in the offshore wind markets in the UK and Germany.

Many of the interviewees from smaller firms stated that Statoil and Statkraft have contributed little to the Norwegian offshore wind supply industry (IEX3, SDE3, SDI, SDE2, SDE5, SDE1). From interviews with representatives from the large firms, we found that the main explanation for this was that these companies operate entirely as global players.

Consequently, the only concern for these large firms is that the suppliers need to be qualified, regardless of home country (IEX2, SDE5, LDI1). 
At the same time, several of the industry representatives we interviewed stated that the engagement by large incumbent firms had opened doors for a number of Norwegian suppliers and that they already played an important role in facilitating access to the international markets and providing smaller firms with the possibilities to gain experience and to have reference projects for their products and services (LDI5). This has been facilitated mostly through the exploitation of existing relations between firms that have previously collaborated in the oil and gas industry (IEX2, LDI4). Thus, the presence of transnational linkages in combination with domestic relations established in a related industry has facilitated access to international markets for some firms.

In sum, firm size matters for two reasons. First, smaller firms appear to be particularly vulnerable to weak local market formation. Small firms will often find it challenging to compete with firms with more resources. This challenge seems to be amplified when there is no domestic market. Second, we find that larger firms can play an important role in the successful development of a supply industry in the absence of a home market. This is because large firms with existing transnational linkages can act as intermediaries and help smaller firms to link up with international markets.

\subsection{Role of related industries}

The third proposition we set out to investigate in this paper is that the presence of markets in closely related industries could compensate for the absence of a home market for offshore wind. In the following, we first describe how experience and competences from these established industries contribute to firms' activities in offshore wind.

A number of previous studies have pointed to the close relationship between the Norwegian oil \& gas and maritime industries and the emerging offshore wind industry (Hanson et al. 2015; Normann 2015; Steen \& Hansen 2014). This relationship is also evident in our data. 
Table 3 showed that more than one-third of the surveyed firms have their primary activity in oil \& gas or maritime industries. Moreover, figure 5 below shows that 61 of all firms $(\sim 60$ per cent) base their activities in offshore wind on experience from oil \& gas, and that these experiences have been exploited throughout the entire OWP supply chain. This tells us that an overwhelming majority of the Norwegian offshore wind suppliers draw upon competences and experience from the petro-maritime industries, and that many of these still operate primarily in this sector.

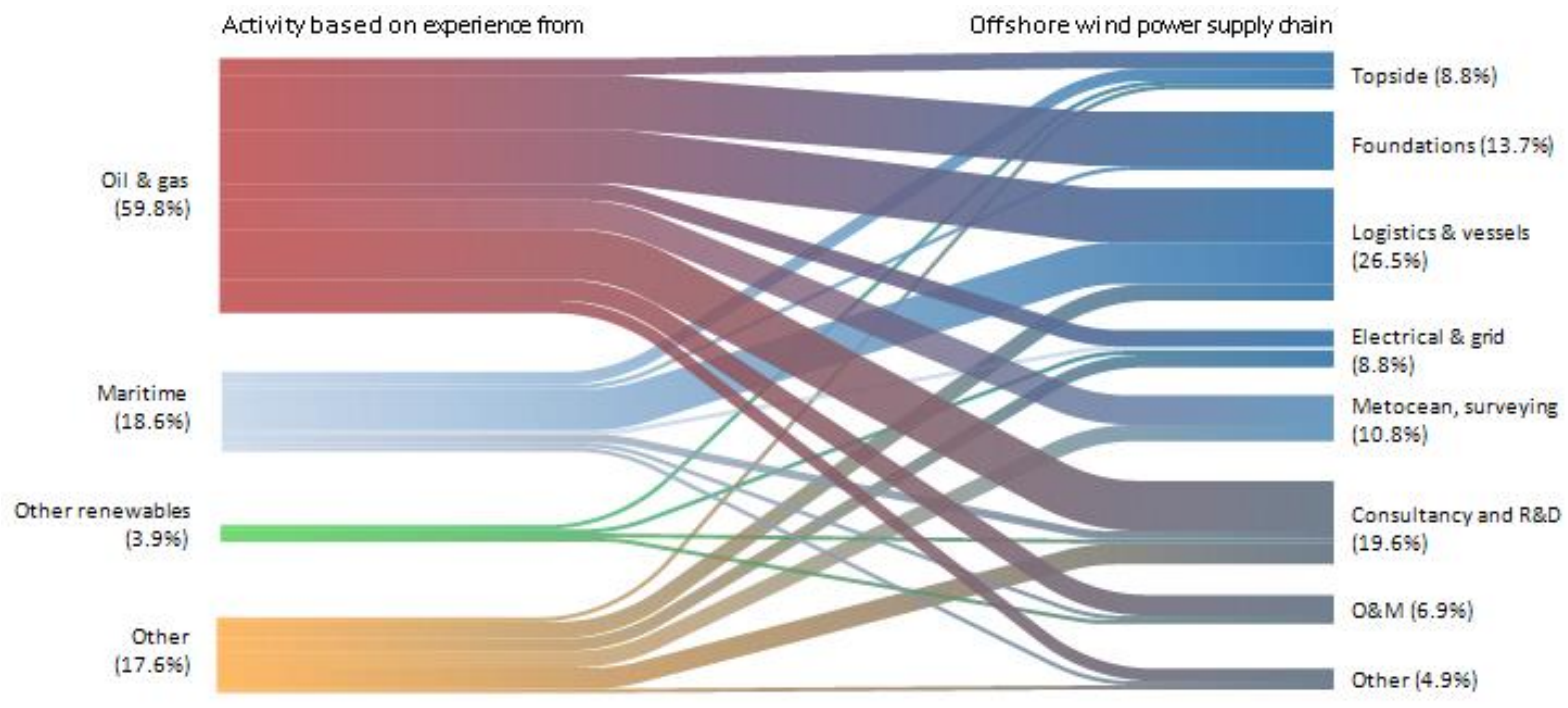

Figure 5. Relation between experience from other industries and OWP supply chain (pct. of firms in brackets).

Note: Based on question in survey: 'Which other industries has firm activity in offshore wind been based on?'

Our interviewees also confirmed that activity in offshore wind draw heavily on competences from oil and gas. More specifically, respondents pointed to competences on offshore structures, moveable objects in offshore environments, metocean (meteorology and oceanography), and maritime installations as important related competences (LDI6, SDI1, SDE5, SDE1, SDE3). For instance, the floating foundation used on Hywind uses a very similar structure as the ones used by floating buoys in oil and gas. Moreover, competences on 
load and response, materials and corrosion, material fatigue, soil conditions and anchoring are all transferable from oil and gas to offshore wind (LDI2).

Further, a number of respondents identified experience from technology qualification processes as relevant (LDI2, SDE5, LDI3). Because of the high costs of replacing faulty equipment and downtime offshore, testing and verification of technology offshore is important, and is competence that actors from the oil and gas industry can draw upon.

Infrastructure resources from the oil \& gas industry such as R\&D labs and harbour facilities was also identified as important for firms' ability to compete in the offshore wind industry (SDI1, SDE4).

In summary, the transfer of knowledge, experience and resources from an established related industry through structural couplings (Bergek et al. 2015, p. 53) have aided the establishment of components in a national offshore wind TIS. Having a well-established and open network in a related industry seems to further facilitate this transfer. One of the respondents emphasised the value of being immersed in a dense oil and gas network stating that:

"The most important competence [from oil and gas industry] is the network. The Norwegian offshore industry is incredibly networked. People are very open to sharing experiences, also to put it bluntly, very confidential things. And it's to everyone's benefit. Geeks don't network is not true" (SDE5).

However, transfer of resources through structural couplings does not necessarily occur without difficulties. Firms with experience from oil and gas need to make changes to meet cost-efficiency demands and standardisation requirements in offshore wind markets. Switching from developing tailor made solutions to serial production of components has been a challenge for several firms. One respondent even claimed that they played down the experience from oil and gas in international tenders because "we have a reputation for being expensive and not very efficient in the oil and gas industry (SDI1)”. 
From the survey data we found that 86 per cent of the firms report that transferring experience from related industries requires at least some adjustments. Moreover, figure 6 shows that a larger share of dedicated firms (22\%) experience that the transferability of experiences from related industries requires major changes when compared with diversified firms (9\%).

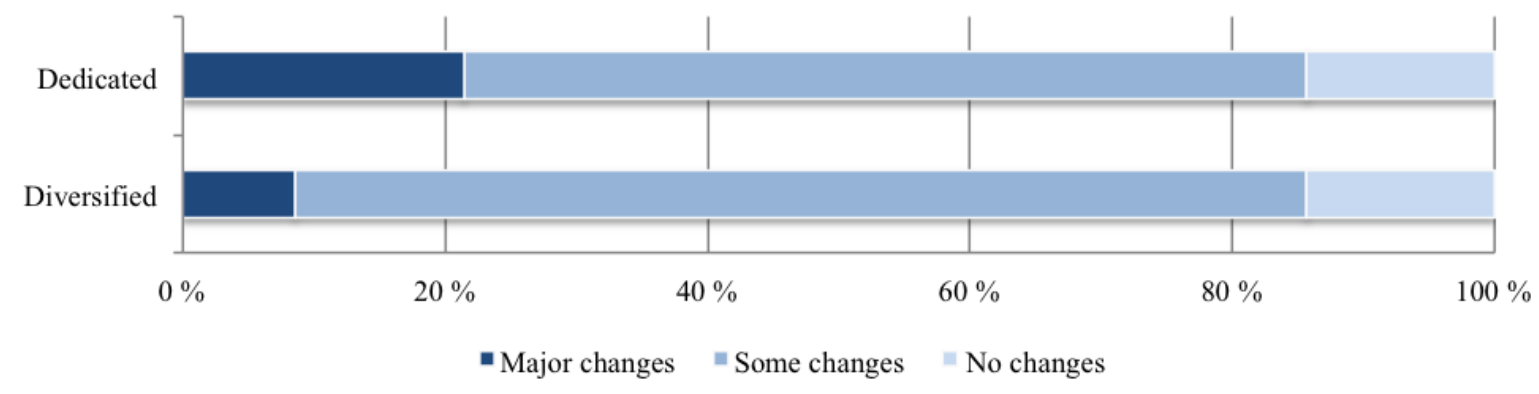

Figure 6. Transferability of experience from other industry to activities in offshore wind.

This corresponds with observations made by Andersen, Drejer, and Gjerding (2014) in a study of the wind industry in Denmark. They explain similar findings by pointing out that diversified firms to a greater extent supply general products and services that can apply to a range of industries. They are therefore to a lesser extent forced to make particular adaptations to for instance the offshore wind industry.

Evidence from interviews lends support to a similar explanation. A respondent from the maritime industry told us that:

"To us, [transferring expertise from maritime to offshore wind] is not problematic because it is, if not entirely the same, more or less the same to build for offshore wind as to offshore oil and gas. Same type of technology, same type of vessel, same type of functionality" (SDI2).

One of the arguments in section 2.2 was that a home market is needed to test and verify new technology for offshore wind. We suggest that firms providing more broadly applicable solutions, such as maritime firms might depend less on the presence of a home market than firms in other industries. As the same respondent put it: 
"The ship-owners that operate in offshore wind are just offshore ship-owners expanding their fleet with offshore wind vessels. It is the same customers as before (...) A small home market in the shape of a demonstration park for offshore wind would mean nothing to us other than an opportunity to build another ship" (SDI2).

In summary, we find that the emerging offshore wind industry in Norway is closely linked to related internationally successful industries. Moreover, we find that these related industries provide opportunities to transfer a range of different resources that are relevant for offshore wind. However, we also observe potential downsides associated with relying too much on resources from these related industries. Several respondents pointed to risks associated with a lack of dedication towards offshore wind:

"A number of [Norwegian] companies have entered and later withdrawn from the wind industry. If there is a slump in oil and gas, then perhaps we should try out wind. If something happens to the oil price again, then we concentrate on oil and gas. You have to stay focused. You've got to stand up as a player who wants something in the industry" (SDE4).

\begin{abstract}
"Over time, you have to acquire a critical mass. Maybe 10 or 20 per cent of revenue. You cannot fiddle about around a few per cent. Because in the next strategy process then, it easily ends up with 'now we have to see where we are going to cut back' and then you cut out those little things on the side. And I think we've seen a lot of that in offshore wind in Norway" (IEX4).
\end{abstract}

A certain critical mass is an important prerequisite for creating an environment that favours dynamic interaction among firms which give rise to new business opportunities (Carlsson \& Stankiewicz 1991, p. 107). Thus, the close relationship between offshore wind and related industries might to some extent also harm the potential for linking up with an international offshore wind TIS.

A consequence of relying heavily on diversified firms (rather than dedicated offshore wind firms) is that there may be competition over resources between industries (SDE1) and within firms (LDI6, LDI2, LDI1), which might lead to insufficient commitment towards diversified activities (Geels et al. 2008). Thus, while we observe that related industries have provided 
opportunities for branching, we also find support for the contention that structural couplings with a related industry can be both enabling and constraining (Bergek et al. 2015, pp. 53-4).

\section{Discussion and conclusions}

In this paper, we have addressed the question of how industries in non-leader countries in terms of market development can link up with an international offshore wind technological innovation system. Drawing on extant literature, we developed three propositions about the role of home markets, firm size and related industries and how these might influence possibilities for internationalisation.

First, we find support for our first proposition in that weak local market formation negatively affects the possibility for many firms to link up with international markets and the opportunity for industries in non-leader countries to link up with international technological innovation systems. Our data points to several areas where a lack of a home market challenges firms' ability to internationalise. Most notably, we see that testing and qualifying technology is an important process in a complex and capital-intensive industry such as offshore wind. Without a home market, this process becomes difficult for firms operating in the market for subcontracts. The majority of these firms have to pursue such sub-contracts to international firms, which is particularly challenging for the many smaller firms operating in this market. Moreover, just as studies of the photovoltaic industry have shown that market formation can contribute positively to other system functions (Dewald \& Truffer 2011), we see that weak local market formation can provide barriers to interaction with other important processes in the TIS such as knowledge production and entrepreneurial experimentation. Carlsson and Stankiewicz (1991) highlight the importance of utilizing technology in contrast to knowledge generation, and that the latter alone not necessarily leads to increased economic performance. In our case we observe that weak market formation can reduce important opportunities for 
utilizing technology and knowledge, which weakens the international competitiveness of some firms.

Second, both survey and interview data confirm the first part of our second proposition in that larger firms are less affected by weak local market formation. We suggest that this is because larger firms have better access to important resources (financial, market access, research). These resources are particularly important in the absence of a home market (Castellacci 2012; Castellacci \& Fevolden 2014). Further, we find that close proximity to the offshore wind markets in the North Sea can diminish some of the challenges associated with weak local market formation. However, we also find that this applies more often to larger firms with existing activities in these markets related to petro-maritime industries. With regards to the second part of the proposition we find that larger firms to some degree have offered opportunities for resource transfer and customer access for small and medium sized firms. However, there remains an unrealized potential as interview data shows that smaller firms miss larger firms that can act as intermediaries to enable international market access.

Third, we find that the offshore wind and petro-maritime industries in Norway are closely intertwined, and that presence of the latter has been a critical enabler of the emergence of a Norwegian supply industry for offshore wind. We thus find support for the proposition that the presence of firms and markets in related industries can offset the effects of weaknesses in the domestic market, amongst others by providing access to customers and resources. However, we also see a duality in the relation between these industries. On the one hand, large diversified firms might enjoy the benefits of access to important resources and access to markets important for both testing of technology and for securing commercial contracts. On the other hand, efforts dedicated to offshore wind are often small compared with the primary activities of these diversified firms. This can make the Norwegian supply industry for 
offshore wind vulnerable to changes at the firm level (i.e. new management or company strategy) and the industry level (increased offshore petroleum activity).

\subsection{Theoretical implications}

Recent studies of international dimensions of TISs have attended to how certain system functions may not be required in all sub-systems as weak functionality for a technology in one country or region may be offset by strengths in other sub-systems. Binz et al. (2014) do however point out that how different actors have differential access to these functions needs further exploring, and in our analysis we have identified some key factors that we understand to influence the potential for internationalization focusing especially on the role of market formation. Wieczorek et al. (2015, p. 140) for instance suggest that lack of "market formation [is] less of a problem if access to neighbouring markets is possible". While the evidence in this paper suggests that it is indeed possible to circumvent challenges of weak domestic market formation by exploiting neighbouring markets, it must be underlined that this is not straightforward and without obstacles because market formation has certain local attributes that may be particularly challenging to transfer, such as facilitating user-producer relations and verification of technology.

In this paper, we have argued that a lack of access to local markets represents a challenge for certain parts of the Norwegian offshore wind supply industry. The importance of local markets will differ across sectors (Malerba \& Nelson 2011) and types of industries (Huenteler et al. 2016). Thus, considering the complexity and size of large offshore wind projects we expect local markets to play a similar important role first and foremost in similar industries characterised by complex products and systems. However, the case of offshore wind in Norway also suggests that the opportunity to access markets in other sub-TISs can differ substantially between segments in a particular industry. The supply industry to offshore wind 
projects consists of a very heterogeneous group of suppliers. We have for instance observed that suppliers in certain segments of the maritime industry (i.e. suppliers of vessels) have found it to be comparatively less problematic to adapt from the petroleum to the offshore wind industries. These firms already benefit from local user-producer relations from access to a local oil and gas market. They might therefore be less reliant on a home market for offshore wind. An opportunity for further research would be to systematically explore these differences across segments within several clean energy industries.

Findings in this study show that technologies and solutions from a related industry have stimulated the supply to an emerging industry. In some cases, this related industry has also provided opportunities to test and develop technology, which has been used in the emerging industry. Moreover, we see that the offshore wind power and offshore petroleum industries request similar products and services indicating demand side relatedness. This shows that overlaps with a related industry can compensate for some of the benefits provided by access to a local market. We must however stress that we see no evidence (yet) of a market for offshore wind power technology in the established offshore petroleum industry. Thus, market access has only been facilitated by local markets or through access to international markets. In conclusion then, our study supports the idea that while supply side relatedness in terms of knowledge and technology is important, new industry formation depends a great deal on local actors' ability to access markets outside the national sub-system (Binz, Truffer, \& Coenen 2016).

Finally, even though access to markets in a separate sub-TIS is possible, our case supports the suggestions in previous studies that weak market formation in a national TIS can negatively influence the development of other functions such as knowledge production and entrepreneurial experimentation in the same sub-system (Jacobsson \& Karltorp 2013; Wieczorek et al. 2015). Our primary concern here has not been to study the formation of a 
national sub-TIS. Rather, our interest has been to analyse why some firms seem to succeed more than others in gaining access to the international TIS for a design-intensive industry such as offshore wind. While all firms could potentially access markets in other sub-TISs, the national sub-TIS in which they are embedded (which in our case lacks local market formation) is not optimal for all types of firms.

\subsection{Policy implications}

In terms of policy, we agree with the Norwegian expert panel recommendation from Energi21 (2014) in that national policy towards the development of local industrial capacity in renewable energy should be adapted to local competitive advantages, opportunities and challenges, and areas of competence. Findings in this paper show how established activities in oil \& gas provide opportunities for offshore wind through competitive advantages and special areas of competence. However, we also find that the close link between oil and gas and OWP can constrain further strengthening of a Norwegian offshore wind supply industry. The aim for policy should therefore be to support the enabling role of offshore and maritime industries and remove some of the constraining features of this relationship. Here, we suggest two ways in which our results might contribute.

Evidence from the Dutch and German offshore wind industries points to the participation of large utilities and incumbent firms as critical for building up a national offshore wind industry (Raven et al. 2016; Reichardt et al. 2016). The Norwegian supply industry for offshore wind consists of mostly smaller firms or firms with minor activities in offshore wind. These firms are particularly challenged by weak local market formation. At the same time, there are large Norwegian firms that participate (or have the potential to participate) in the international offshore wind TIS. These firms have to a limited extent contributed to the build-up of a national offshore wind cluster (Normann in press). One goal for policy could be to stimulate 
interaction between smaller and larger firms, given the potential role of larger firms as intermediaries, which can help suppliers with access to financial and research resources and international markets. Policies that reward the use of local suppliers are unlikely to be approved under the European rules on free competition. Indeed, we support the argument by Reichardt et al. (2016) that local content policies as observed in the UK can limit opportunities for transnational linkages and as such weaken the overall performance of the European offshore wind TIS. However, policy might be designed to facilitate increased interaction between small technology firms and larger industrial firms, for instance through joint R\&D and demonstration that target consortia of smaller and larger firms. Finally, policy could make it more economically attractive for larger firms to locate demonstration projects in Norway.

Following from the above, increased participation from large incumbents might also be achieved by strengthening and incentivizing diversification activities in firms established in related industries. As many companies are diversifiers with minor OWP activities we see a need to maintain or strengthen OWP in diversified firms also during periods when activity levels in oil and gas are high. On the one hand, the current slump in offshore oil and gas investments might facilitate further diversification activities from oil and gas to other industries such as OWP. On the other hand, incumbents' reaction to changing selection pressures can be slow and transforming business activities can be incredibly difficult for incumbent firms (Leonard-Barton 1992). Thus, we see the current decline in oil and gas as an opportunity for public policy to encourage diversification processes.

\section{Acknowledgements}

We gratefully acknowledge constructive comments on earlier drafts from Jan Fagerberg, Christine Mee Lie, Keith Smith and two anonymous reviewers. We also wish to thank all 
interviewees who took time to talk to us despite busy schedules. Research for this paper has been funded by Centre for Sustainable Energy Studies (CenSES), grant 209697/E20 from the Research Council of Norway. 


\section{References}

Acs, Z., \& Terjesen, S. (2013). Born local: toward a theory of new venture's choice of internationalization. Small Business Economics, 41(3), 521-35.

Andersen, P. H., Drejer, I., \& Gjerding, A. N. (2014). Branching and path development in the wind energy industry. Paper presented at 11th European Network on the Economics of the FIRM (ENEF), Manchester Institute of Innovation Research (MIOIR).

Banerjee, N., Song, L., \& Hasemyer, D. (2015, 2015, September 16). Exxon's Own Research Confirmed Fossil Fuels' Role in Global Warming Decades Ago. Retrieved 2016, February 1, from http://insideclimatenews.org/news/15092015/Exxons-own-research-confirmed-fossilfuels-role-in-global-warming

Bennett, A., \& Braumoeller, B. (n.d.). Where the Model Frequently Meets the Road: Combining Statistical, Formal, and Case Study Methods. Working paper.

Bergek, A., Hekkert, M., Jacobsson, S., Markard, J., Sandén, B., \& Truffer, B. (2015). Technological innovation systems in contexts: Conceptualizing contextual structures and interaction dynamics. Environmental Innovation and Societal Transitions, 16, 51-64.

Bergek, A., Jacobsson, S., Carlsson, B., Lindmark, S., \& Rickne, A. (2008). Analyzing the functional dynamics of technological innovation systems: A scheme of analysis. Research Policy, 37(3), 407-29.

Binz, C., Truffer, B., \& Coenen, L. (2014). Why space matters in technological innovation systems Mapping global knowledge dynamics of membrane bioreactor technology. Research Policy, 43(1), 138-55.

Binz, C., Truffer, B., \& Coenen, L. (2016). Path Creation as a Process of Resource Alignment and Anchoring: Industry Formation for On-Site Water Recycling in Beijing. Economic Geography, 92(2), 172-200.

Binz, C., Truffer, B., Li, L., Shi, Y., \& Lu, Y. (2012). Conceptualizing leapfrogging with spatially coupled innovation systems: The case of onsite wastewater treatment in China. Technological Forecasting and Social Change, 79(1), 155-71.

Carlsson, B., Jacobsson, S., Holmén, M., \& Rickne, A. (2002). Innovation systems: analytical and methodological issues. Research Policy, 31(2), 233-45.

Carlsson, B., \& Stankiewicz, R. (1991). On the nature, function and composition of technological systems. Journal of Evolutionary Economics, 1(2), 93-118. 
Castellacci, F. (2012). Firm's internationalisation in the service industries: Evidence from Norway. In H. Hveem \& C. H. Knutsen (Eds.), Governance and knowledge : the politics of foreign investment, technology and ideas (Vol. 18, pp. 199-217). London: Routledge.

Castellacci, F., \& Fevolden, A. (2014). Capable Companies or Changing Markets? Explaining the Export Performance of Firms in the Defence Industry. Defence and Peace Economics, 25(6), $549-75$

Coady, D., Parry, I., Sears, L., \& Shang, B. (2015). How Large Are Global Energy Subsidies?, IMF Working Paper. International Monetary Fund.

Coenen, L., Benneworth, P., \& Truffer, B. (2012). Toward a spatial perspective on sustainability transitions. Research Policy, 41(6), 968-79.

Damanpour, F. (1992). Organizational size and innovation. Organization studies, 13(3), 375-402.

Dass, P. (2000). Relationship of Firm Size, Initial Diversification, and Internationalization with Strategic Change. Journal of Business Research, 48(2), 135-46.

Dewald, U., \& Truffer, B. (2011). Market Formation in Technological Innovation Systems-Diffusion of Photovoltaic Applications in Germany. Industry and Innovation, 18(3), 285-300.

Dewald, U., \& Truffer, B. (2012). The Local Sources of Market Formation: Explaining Regional Growth Differentials in German Photovoltaic Markets. European Planning Studies, 20(3), $397-420$.

Energi21 (2014). Strategi 2014 - Nasjonal strategi for forskning, utvikling, demonstrasjon og kommersialisering av ny energiteknologi. Oslo.

EWEA (2015). European Offshore Statistics 2014, European Wind Energy Association.

Fagerberg, J. (1992). The Home Market Hypothesis Re-examined: The Impact of Domestic UserProducer Interaction on Export Specialisation. In B.-Å. Lundvall (Ed.), National Systems of Innovation. Towards a Theory of Innovation and Interactive Learning (pp. 226-41). London: Pinter.

Fagerberg, J. (1995). User-producer interaction, learning and comparative advantage. Cambridge Journal of Economics, 19(1), 243-56.

Freeman, C. (1987). Technology, policy, and economic performance : lessons from Japan. London ; New York: Pinter Publishers.

Freeman, C. (1995). The 'National System of Innovation' in historical perspective. Cambridge Journal of Economics, 19(1), 5-24. 
Frenken, K., \& Boschma, R. A. (2007). A theoretical framework for evolutionary economic geography: industrial dynamics and urban growth as a branching process. Journal of Economic Geography, 7(5), 635-49.

Geels, F. W. (2014). Regime Resistance against Low-Carbon Transitions: Introducing Politics and Power into the Multi-Level Perspective. Theory, Culture \& Society, 31(5), 21-40.

Geels, F. W., Hekkert, M. P., \& Jacobsson, S. (2008). The dynamics of sustainable innovation journeys. Technology Analysis \& Strategic Management, 20(5), 521-36.

Gosens, J., Lu, Y., \& Coenen, L. (2015). The role of transnational dimensions in emerging economy 'Technological Innovation Systems' for clean-tech. Journal of Cleaner Production, 86, 37888.

Hansen, G. H., \& Steen, M. (2012). Renewable detours - offshore oil and gas firms as transition actors. Paper presented at International Conference on Sustainability Transitions (IST), Copenhagen.

Hansen, G. H., \& Steen, M. (2015). Offshore oil and gas firms' involvement in offshore wind: Technological frames and undercurrents. Environmental Innovation and Societal Transitions, $17,1-14$.

Hansen, T., \& Coenen, L. (2015). The geography of sustainability transitions: Review, synthesis and reflections on an emergent research field. Environmental Innovation and Societal Transitions, 17, 92-109.

Hanson, J., Steen, M., Weaver, T., Normann, H. E., \& Hansen, G. H. (2015). Complementarities and relatedness in established and emerging path interlinkages. Paper presented at International Sustainability Transitions Conference, Brighton, UK.

Hekkert, M. P., Suurs, R. A. A., Negro, S. O., Kuhlmann, S., \& Smits, R. E. H. M. (2007). Functions of innovation systems: A new approach for analysing technological change. Technological Forecasting and Social Change, 74(4), 413-32.

Hockerts, K., \& Wüstenhagen, R. (2010). Greening Goliaths versus emerging Davids — Theorizing about the role of incumbents and new entrants in sustainable entrepreneurship. Journal of Business Venturing, 25(5), 481-92.

Howells, J. (2006). Intermediation and the role of intermediaries in innovation. Research Policy, 35(5), 715-28.

Huenteler, J., Schmidt, T. S., Ossenbrink, J., \& Hoffmann, V. H. (2016). Technology life-cycles in the energy sector - Technological characteristics and the role of deployment for innovation. Technological Forecasting and Social Change, 104, 102-21. 
Jacobsson, S., \& Bergek, A. (2004). Transforming the energy sector: the evolution of technological systems in renewable energy technology. Industrial and Corporate Change, 13(5), 815-49.

Jacobsson, S., \& Karltorp, K. (2013). Mechanisms blocking the dynamics of the European offshore wind energy innovation system - Challenges for policy intervention. Energy Policy, 63, 118295.

Kaldellis, J. K., \& Kapsali, M. (2013). Shifting towards offshore wind energy—Recent activity and future development. Energy Policy, 53, 136-48.

King, D. R., Covin, J. G., \& Hegarty, W. H. (2003). Complementary resources and the exploitation of technological innovations. Journal of Management, 29(4), 589-606.

Leonard-Barton, D. (1992). Core Capabilities and Core Rigidities: A Paradox in Managing New Product Development. Strategic Management Journal, 13, 111-25.

Lundvall, B.-Å. (1988). Innovation as an interactive process: from user-producer interaction to the national system of innovation. In G. Dosi, C. Freeman, R. Nelson, G. Silverberg \& L. Soete (Eds.), Technical Change and Economic Theory (pp. 349-69). London: Pinter Publishers.

Lundvall, B.-Å. (1992). User-Producer Relationships, National Systems of Innovation and Internationalisation. In B.-Å. Lundvall (Ed.), National Systems of Innovation. Towards a Theory of Innovation and Interactive Learning (pp. 56-83). London: Pinter.

Lundvall, B.-Å., Johnson, B., Andersen, E. S., \& Dalum, B. (2002). National systems of production, innovation and competence building. Research Policy, 31(2), 213-31.

Mahoney, J., \& Goertz, G. (2006). A Tale of Two Cultures: Contrasting Quantitative and Qualitative Research. Political Analysis, 14(3), 227-49.

Make Consulting (2016). Norwegian Opportunities in Offshore Wind. Produced for INTPOW, Export Credit Norway and Greater Stavanger.

Malerba, F., \& Nelson, R. (2011). Learning and catching up in different sectoral systems: evidence from six industries. Industrial and Corporate Change, 20(6), 1645-75.

Markard, J., Raven, R., \& Truffer, B. (2012). Sustainability transitions: An emerging field of research and its prospects. Research Policy, 41(6), 955-67.

Normann, H. E. (2015). The role of politics in sustainable transitions: The rise and decline of offshore wind in Norway. Environmental Innovation and Societal Transitions, 15, 180-93.

Normann, H. E. (in press). Policy networks in energy transitions: The cases of carbon capture and storage and offshore wind in Norway. Technological Forecasting and Social Change. 
Porter, M. E. (1998). The competitive advantage of nations: with a new introduction. Basingstoke: Macmillan Business.

Quitzow, R. (2015a). A dynamic perspective on environmental innovation and national competitiveness - an assessment of policy and empirical evidence from the solar energy sector. Doctoral thesis, Freie Universität Berlin.

Quitzow, R. (2015b). Dynamics of a policy-driven market: The co-evolution of technological innovation systems for solar photovoltaics in China and Germany. Environmental Innovation and Societal Transitions, 17, 126-48.

Rajagopalan, N., \& Spreitzer, G. M. (1997). Toward a Theory of Strategic Change: A Multi-lens Perspective and Integrative Framework. The Academy of Management Review, 22(1), 48-79.

Raven, R., Kern, F., Verhees, B., \& Smith, A. (2016). Niche construction and empowerment through socio-political work. A meta-analysis of six low-carbon technology cases. Environmental Innovation and Societal Transitions, 18, 164-80.

Reichardt, K., Negro, S. O., Rogge, K. S., \& Hekkert, M. P. (2016). Analyzing interdependencies between policy mixes and technological innovation systems: The case of offshore wind in Germany. Technological Forecasting and Social Change, 106, 11-21.

Smink, M. M. (2015). Incumbents and institutions in sustainability transitions. PhD thesis, Utrecht University.

Smith, A., Stehly, T., \& Musial, W. (2015). 2014-2015 Offshore Wind Technologies Market Report, U. S. D. o. E. National Renewable Energy Laboratory.

Steen, M., \& Hansen, G. H. (2014). Same Sea, Different Ponds: Cross-Sectorial Knowledge Spillovers in the North Sea. European Planning Studies, 22(10), 2030-49.

Truffer, B., \& Coenen, L. (2012). Environmental Innovation and Sustainability Transitions in Regional Studies. Regional Studies, 46(1), 1-21.

Utterback, J. M., \& Suarez, F. F. (1993). Innovation, competition, and industry structure. Research Policy, 22(1), 1-21.

Vasseur, V., Kamp, L. M., \& Negro, S. O. (2013). A comparative analysis of Photovoltaic Technological Innovation Systems including international dimensions: the cases of Japan and The Netherlands. Journal of Cleaner Production, 48, 200-10.

Vatne, E. (2008). Olje og gass - en ny næring i hurtig vekst. In A. Isaksen, A. Karlsen \& B. Sæther (Eds.), Innovasjoner i norske naringer - et geografisk perspektiv (pp. 101-20). Bergen: Fagbokforlaget. 
Volden, G. H., Bull-Berg, H., Skjeret, F., Finne, H., \& Hofmann, M. (2009). Vindkraft offshore og industrielle muligheter. Sintef.

Wieczorek, A. J., Hekkert, M. P., Coenen, L., \& Harmsen, R. (2015). Broadening the national focus in technological innovation system analysis: The case of offshore wind. Environmental Innovation and Societal Transitions, 14, 128-48. 